\section{ADHD and obesity}

I read with interest the commentary by Valerie H. Taylor et al..$^{1}$ on eating behaviour and obesity. As the authors state, not everyone exposed to high-fat, high-calorie foods becomes overeaters. Only those with specific vulnerability of impulsive behaviours show a tendency to be food addicts. However, the impulsivity is closely related to attentiondeficit hyperactivity disorder (ADHD). There have been a few clinical investigations that suggest ADHD may be a comorbidity of obesity. The underlying mechanism is unknown.

One of the accepted hypotheses ${ }^{2}$ is that ADHD, or ADHD symptoms of impulsivity or attention deficit, plays an important role in developing abnormal eating behaviours, which contribute to obesity. For the treatment of the subset with both ADHD and obesity, improvement of the ADHD symptoms may reduce weight. So in addition to screening for addiction and binge eating in obese population, ADHD should be evaluated.

\section{Rongwang Yang MD}

The Children's Hospital, Zhejiang University School of Medicine, Hangzhou, China

\section{REFERENCES}

1. Taylor VH, Curtis CM, Davis C. The obesity epidemic: the role of addiction. CMAJ 2009 Dec. 21 [Epub ahead of print].

2. Cortese S, Angriman M, Maffeis C, Isnard P, et al. Attention-deficit/hyperactivity disorder (ADHD) and obesity: a systematic review of the literature. Crit Rev Food Sci Nutr 2008;48:524-37.

For the full letter, go to: www.cmaj.ca/cgi/eletters /cmaj.091142v1\#266430

DOI:10.1503/cmaj.110-2026

\section{Defining high risk}

The article "Proliferation of prenatal ultrasonography" is commendable as an attempt to define current trends in prenatal ultrasonography. However, a population-based study has an inherent weakness, i.e. completeness of case ascertainment, potentially resulting in incorrect assignment of cases to the wrong study group. In this study, patients were "high risk" if they met one of four criteria. All others were "low risk." This strategy would result in incorrect assignment of a major proportion of high-risk pregnancies to the low-risk group. Although it is possible that more low-risk women are having repeated scans today compared to 10 years ago, it is quite likely that this study has significantly overestimated this problem due to the weakness in study design as discussed above thereby failing to include all the high risk pregnancies in the high risk group.

\section{Venu Jain MD PhD}

Maternal-Fetal Medicine/Obstetrics and Gynecology, Royal Alexandra Hospital, University of Alberta, Edmonton, Alta.

\section{REFERENCE}

1. You JJ, Alter DA, Stukel TA, et al. Proliferation of prenatal ultrasonography. CMAJ 2010;182:143-51.

For the full letter, go to: www.cmaj.ca/cgi/eletters /cmaj.090979v1\#263941

DOI:10.1503/cmaj.110-2021

\section{The authors respond:}

We thank Dr. Jain for his interest in our paper. ${ }^{1}$ We agree that the lack of clinical detail is a limitation of our study. However, while we may have misclassified some high-risk pregnancies as low risk, the same is probably also true for lowrisk pregnancies. We used a consistent definition of high risk throughout the study period and one would not expect the proportion of high-risk pregnancies to increase greatly over the time period of our study. Moreover, in the final year of our study, almost one in every five singleton pregnancies was classified as high risk, which would suggest that we used an inclusive definition of high risk.

\section{John J. You MD}

Department of Medicine, McMaster

University, Hamilton, Ont.

\section{REFERENCES}

1. You JJ, Alter DA, Stukel TA, et al. Proliferation of prenatal ultrasonography. CMAJ 2010;182:143-51.

For the full letter, go to: www.cmaj.ca/cgi/eletters /cmaj.090979v1\#269362

DOI:10.1503/cmaj.110-2031

\section{Physicians lead reform}

The article "Physicians pressed to play nice"1 unfairly characterizes physicians as being inflexible in encouraging collaboration when nothing could be further from the truth. Ontario's doctors are national leaders in primary care reform, with more than 7500 doctors in collaborative care models providing service to over 8.5 million patients in Ontario. We are committed to being at the forefront of building a stronger, higher quality health care system for our patients.

\section{Suzanne Strasberg MD}

President, Ontario Medical Association, Toronto, Ont.

\section{REFERENCES}

1. Webster PC. Physicians pressed to play nice. CMAJ 2010 Feb. 1 [Epub ahead of print].

For the full letter, go to: www.cmaj.ca/cgi/eletters /cmaj.109-3163v2\#271636

DOI:10.1503/cmaj.110-2034

\section{Correction}

The article "Unacceptable status quo in access to mental health care," ${ }^{\prime \prime}$ published Jan. 12, said that 600000 Canadians meet criteria for a diagnosable mental disorder. In fact, that number is six million. CMAJ regrets any inconvenience this error may have caused.

\section{REFERENCE}

1. Goldbloom DS. Unacceptable status quo in access to mental health care. CMAJ 2010;182:112

DOI:10.1503/cmaj.110-2038

\section{Letters to the editor}

In submitting a letter, you automatically consent to have it appear online and/or in print. All letters accepted for print will be edited by $C M A J$ for space and style. Most references and multiple authors' names and full affiliations will appear online only. (The full version of any letter accepted for print will be posted at cmaj.ca.) 